\title{
Erratum zu: Bioökonomie im Selbststudium: Nachhaltigkeit und ökologische Bewertung
}

\section{Erratum zu: \\ C. Rösch et al., Bioökonomie im Selbststudium: Nachhaltigkeit und ökologische Bewertung, Zertifikatskurs Bioökonomie, https://doi.org/10.1007/978-3-662-61383-2}

Folgende Änderungen wurden ausgeführt:

Seite III: Eine Co-Autorin, Frau Martina Haase, wurde hinzugefügt.

Seite IV: Die Adresse der Co-Autorin wurde hinzugefügt

Die aktualisierte Version der Produktseite kann abgerufen werden unter: https://doi. org/10.1007/978-3-662-61383-2 